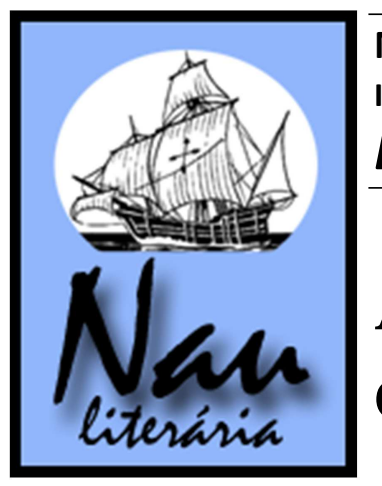

\title{
A metaficção na criação de Natália, de Helder Macedo
}

\section{Andre Leite Costa}

Resumo: Proposta de análise da maneira como Helder Macedo aborda as questões da criação literária no romance Natália. Investiga como o autor apresenta questões metaficcionais e algumas teorias literárias, como a Teoria da Recepção, ao longo do seu livro.

Palavras-chaves: Metaficção, recepção, criação literária.

\begin{abstract}
This article proposes to analyze the way Helder Macedo deals with the literary creation in the novel Natália. It investigates the way the author treats metafiction and some literary theories, as the Theory of Reception, in his novel.
\end{abstract}

Keywords: Metafiction, reception, literary creation.

Quando Helder Macedo decide por escrever sua obra em forma de diário, ele tenta desde o início abrir uma discussão sobre a criação literária. Natália é um romance escrito em primeira pessoa pela personagem principal. Dessa maneira, Macedo, através da mímese e da verossimilhança, procura conferir um senso de sinceridade a seu livro.

\section{Como explica Lígia Militz da Costa:}

Verossimilhança: critério fundamental do conceito aristotélico de mímese, responsável pela distinção entre a obra do poeta e do historiador. Representar o verossímil, na mimese, significa que o objeto da representação do poeta não é o que realmente aconteceu, mas o que poderia acontecer, isto é, o possível. (COSTA, 2006)

Macedo faz com que as palavras de Natália, aparentemente, cheguem diretamente a nós, sem sua mediação de autor. O que poderia parecer uma narrativa fria dos fatos, acaba por se transformar em um relato mais pessoal, o que ajuda a estabelecer a veracidade da história: uma história possível de ter acontecido, o diário que estamos a ler.

O romance é organizado de maneira que cada capítulo descreve um dia, ou partes de um mesmo dia, na vida de Natália. Essa estrutura de diário permite que Macedo, no decorrer da obra, questione o leitor se o que ele está lendo pode realmente ser considerado um livro; e essa é uma das interrogações mais fortes do seu romance: quando simples anotações tornamse, de fato, uma obra literária?

Já no começo do primeiro capítulo, Helder Macedo apresenta os motivos que levaram Natália a dar início à escrita de seu diário. Durante uma entrevista com um escritor para um 
programa de televisão, Natália questiona como o autor faz para escrever seus livros e pergunta qual a melhor maneira de ela escrever o seu próprio romance. $\mathrm{O}$ entrevistado sugere a Natália que uma boa estratégia seria escrever um diário, tomando nota de tudo que acontece em sua vida, para depois organizar suas anotações em forma de um livro:

2000

Sexta-feira, 3 de novembro

Ora bem, vou começar assim para ver no que isto vai dar. Fazendo uma espécie de diário que depois logo se vê se poderei reorganizar em um livro como deve ser. Ou seja: vou tentar seguir o conselho de um escritor que entrevistei há já algum tempo, na última entrevista que fiz na televisão. Evitar as pomposidades que teriam sido a minha tendência natural de menina formada em letras. E que foi como tinha começado, antes de apagar tudo e voltar à página em branco. Que é como quem diz, ao vidro branco na esquadria azul do computador. (MACEDO, 2010)

O que Macedo mostra, no princípio do livro, é que Natália inicia a escrever sua história em um estilo literário, que ela logo acaba por descartar ao apagar as primeiras linhas do seu livro, para então recomeçar sua escrita em uma maneira mais despojada, seguindo os conselhos dados pelo entrevistado. Logo, Helder Macedo, desde o início, procura negar que o que lemos é uma obra literária. Quando Natália percebe que está começando a escrever seu livro como um escritor tradicionalmente faria, o que seria natural levando em conta sua formação acadêmica, ela desiste dessa forma de escrita e volta ao zero, para só então reiniciar a escrever mais informalmente.

A escolha de Helder Macedo por Natália para protagonizar seu romance é muito acertada, já que o autor propõe-se a abordar algumas questões metaficcionais em sua obra. Nada melhor que optar por uma personagem que possui conhecimento das teorias literárias. E assim sendo, o que segue no decorrer do livro é Natália questionando-se continuamente sobre a validade de sua escrita: "Digo à Fátima que estou a escrever um livro, um romance? Mas sei lá se isto é um romance." (MACEDO, 2010); "Mas quando é que um diário termina? E quando é que um romance não é um diário?” (MACEDO, 2010).

Essa é uma das grandes questões abordadas na obra de Helder Macedo: quando as anotações do diário de Natália poderiam vir a tornar-se um livro. De acordo com a Teoria da Recepção, isso não poderia acontecer, por não haver a interação com o público, que se tornou parte importante da construção literária a partir das idéias de Hans Robert Jauss, o qual, “em 1967, exigiu a renovação da história da literatura, dando a prioridade analítica ao aspecto da recepção sobre os da produção e da representação." (STIERLE, 1979).

\footnotetext{
* Possui graduação em Letras pela PUCRS (2007) e Especialização em Língua Inglesa pela PUCRS (2008)
} 
A partir da introdução desses novos conceitos no campo da crítica literária, houve uma mudança no foco com que as obras eram analisadas. Diferente de formalistas e estruturalistas, que consideravam apenas a organização das estruturas internas dos livros, sem qualquer influência do público, a Teoria da Recepção valorizou esse público como parte importante na construção das obras.

É em meio dos questionamentos que abrem o livro que Helder Macedo apresenta Natália. Ela é uma personagem que não conhece muito de si mesma. Natália se conhece à medida em que escreve sua vida nas páginas de seu diário. Helder Macedo faz com que personagem e enredo sejam criados simultaneamente.

\section{Como escreve Candido:}

Geralmente, da leitura de um romance fica a impressão de uma série de fatos, organizados em enredo, e de personagens que vivem esses fatos. É uma impressão praticamente indissolúvel (...) $\mathrm{O}$ enredo existe através das personagens; as personagens vivem no enredo. Enredo e personagem exprimem, ligados, os intuitos do romance, a visão da vida que decorre dele, os significados e valores que o animam. (CANDIDO, 1981)

Utilizando o diário, uma das formas mais básicas de narração em primeira pessoa, sem ter certeza de seu passado e sem saber como a história vai acabar, Helder Macedo faz com que Natália elabore o enredo à medida em que o vive. E assim, busca descobrir quem ela efetivamente é.

Filha de pais que morreram quando ainda era um bebê, todo o conhecimento do seu próprio passado provém de histórias que seu avô conta, sendo que algumas dessas ela nem mesmo tem certeza de serem verdadeiras:

Ouve lá, o Avô contava-te histórias?

Histórias?

Sim, histórias inventadas por ele. Às vezes tiradas dos livros. A explicar como são as coisas sem ter de explicar. Como a mim. (MACEDO, 2010)

Isso gera muitas dúvidas e uma grande confusão na cabeça de Natália. Ela não sabe ao certo o dia do seu nascimento: "Em que mês nasceste? (...) Setembro. 27. E tu em Dezembro. Pois é, no Natal. Por isso Natália. Mas não sei o dia exato.” (MACEDO, 2010). Questiona ser realmente a filha dos pais que não conheceu: "Bem basta não ter tido pai e mãe que tivesse conhecido, mas de repente poder imaginar que não sou quem julgava ser mas, (...) outra filha, (...) que tivessem entregado ao Avô quando ele foi resgatar-me, isso não sei como aguentaria." (MACEDO, 2010) Até mesmo duvida se seu nome é verdadeiro:

Natália não é o meu nome. Esse foi o nome que me deu o homem que matou o meu pai e a minha mãe. (...) Certamente não é o nome que os meus pais me deram. Teria sido demasiada 
coincidência, é impossível que seja o nome que os meus pais me teriam dado. É impossível que Natália seja o meu nome. (MACEDO, 2010)

Tais dúvidas e problemas de identidade acabam gerando uma dificuldade na maneira como Natália relaciona-se com as demais personagens. Ela sente-se usada como um corpo intermediário pelo marido que queria apenas chegar ao seu avô; usada pelo amante artista plástico que a transforma em uma de suas instalações durante seus encontros; e usada por Fátima que quase rouba a sua identidade quando sua presença acaba confundindo Natália que passa a não ter mais certeza sobre quem seria a verdadeira filha dos seus pais.

No meio das desconfianças e confusões, Natália redige seu diário. Ela escreve tudo o que acontece em sua vida e só depois de escrito é que as coisas parecem terem acontecido de fato. E nessa busca de Natália por descobrir quem ela realmente é, a personagem mergulha cada vez mais em seu passado atrás de suas origens.

Quando descobre ter sido salva pelo assassino de seus pais, que esse assassino era um policial cumprindo seu dever e que, dependendo do ponto de vista, ele estava fazendo o bem, e os pais de Natália, que eram revolucionários e que estavam planejando um ataque terrorista, é que eram os verdadeiros assassinos, a personagem se confunde cada vez mais:

se calhar o homem achava mesmo que era tudo a bem da nação. Se calhar achava mesmo que era um servidor da pátria. Como meus pais achavam que estavam a lutar por uma boa causa, a servir a pátria a sua maneira. Tal como o outro, a bem da nação. Na luta armada, o quer que isso fosse. (...) A minha mãe grávida de mim a preparar mortes. (...) Execuções de gente repugnante, como o outro que me salvou? Mas se calhar para o outro os meus pais é que eram os repugnantes. (MACEDO, 2010)

Cada descoberta que poderia ajudar em seu autoconhecimento acaba por dificultar a busca por identidade, e essa confusão afeta a maneira como Natália escreve: "escrever alguma coisa que faça sentido é mais complicado do que eu julgava, Senhor Escritor da Entrevista." (MACEDO, 2010). Quanto mais ela sente dificuldade em saber quem é, mais difícil é escrever. E assim, Natália abandona seu diário, sem ter conseguido entender tudo o que lhe aconteceu. Alguns anos depois relê o que escreveu e só então as coisas começam a fazer algum sentido para ela.

Helder Macedo escolheu a estrutura de diário para seu romance na tentativa de utilizar o aspecto da incerteza determinada pelo uso dessa forma. Dessa maneira, pôde construir seus personagens à medida que o enredo se desenvolvia. Natália só percebia que as coisas realmente aconteciam depois de escritas por ela, como um livro só vem a tomar forma quando seu autor o elabora. Depois de um distanciamento da escritora, Natália encara seu diário como uma leitora e só assim, depois de sua contribuição como receptora, a história pode fazer algum sentido para ela mesma, e o livro pode ter um fim. 


\section{Referências}

CANDIDO, Antonio; ROSENFELD, Anatol; PRADO, Decio de Almeida; GOMES, Paulo Emillio Sales. A personagem de ficção. São Paulo: Perspectiva, 1981.

COSTA, Lígia Militz da. A poética de Aristóteles, mímese e verossimilhança. São Paulo: Ática, 2006.

JAUSS, Hans Robert; ISER, Wolfgang; STIERLE, Karlheinz; GUMBRECHT, Hans Ulrich. A literatura e o leitor: textos de estética da recepção. Rio de Janeiro: Paz e terra, 1979.

MACEDO, Helder. Natália. Rio de Janeiro: Beco do Azougue, 2010. 